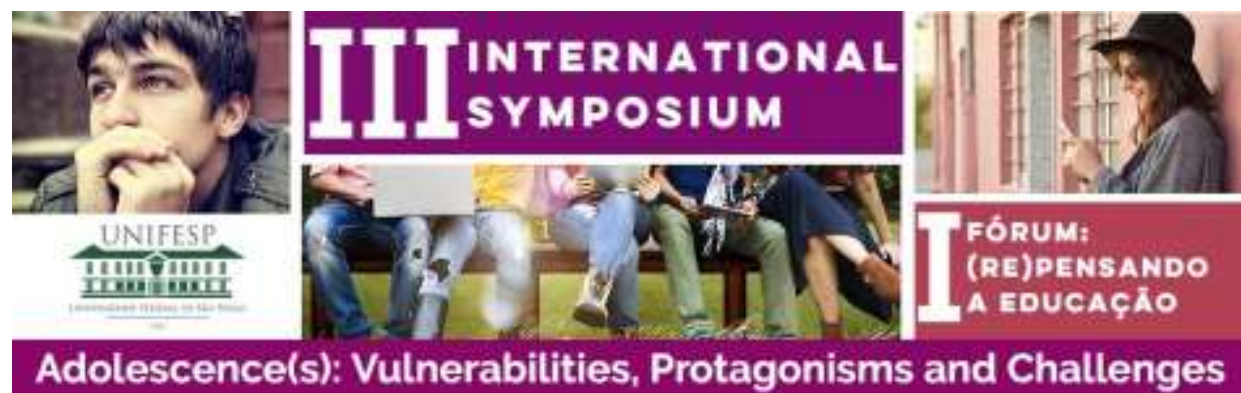

\title{
THE DIFFERENT FORMS OF RELATIONSHIP IN THE DRAWING STEVEN UNIVERSE
}

\section{AS DIFERENTES FORMAS DE RELACIONAMENTO NO DESENHO STEVEN UNIVERSO}

Miguel Gatto Leme'; Márcia Cordeiro²; Ana Laura Schliemann³

1. Miguel Gatto Leme, aluno do curso de graduação de psicologia da faculdade Pontifícia Universidade Católica de São Paulo

E-mail: miguel.gatto16@gmail.com

2. Márcia Cordeiro, aluna do curso de graduação de psicologia da faculdade Pontifícia Universidade Católica de São Paulo

E-mail: macord@uol.com.br

3. Ana Laura Schliemann, docente do curso de graduação em psicologia da Pontificia Universidade Católica de São Paulo

E-mail: alschliemann@pucsp.br

* Pesquisa pertencente ao grupo de pesquisa de desenvolvimento infantil e desenho da faculdade Pontifícia Universidade Católica de São Paulo

\section{Como citar:}

LEME, Miguel Gatto; CORDEIRO, Márcia; SCHLIEMANN, Ana Laura. The different forms of relationship in the drawing steven universe. In: INTERNATIONAL SYMPOSIUM ADOLESCENCE(S) \& FÓRUM (RE)PENSANDO A EDUCAÇÃO, 3, 2017, São Paulo. Anais... São Paulo: Unifesp, 2017. p. 39-40. DOI: http://dx.doi.org/10.22388/2525-5894.2017.018

Introdução: O objetivo desse trabalho é mostrar a análise dos personagens do desenho "Steven Universo", tendo como foco da reflexão o papel sexual na construção do "eu" em cada protagonista da série.

Adotou-se a abordagem psicanalítica que olha para o homem como um sujeito bissexual.

A série "Steven Universo" foi escolhida por tratar-se de uma construção que difere do modelo nuclear, pai, mãe e filhos. Ela é uma série de desenho animado norte-americano criada por Rebecca Sugar (2013) que é produzida pelo canal de televisão Cartoon Network. 
O desenho é coming-of-age, mostra o desenvolvimento da infância até a vida adulta, que conta a história de Steven, um rapaz de 14 anos de idade, membro das Crystal Gems, uma equipe de guardiãs humanóides extraterrestres. Rose Quartz (mãe de Steven) é bissexual, se relaciona com a sua guardiã e com Greg.

Objetivo: O objetivo foi investigar as diferentes formas de relacionamentos que o desenho Steven Universo apresenta.

Métodos: O trabalho foi qualitativo e documental. Analisou a sexualidade a partir da primeira temporada do desenho Steven Universo (2013), Utilizaram-se vinte e cinco episódios da primeira temporada da série, sendo que cada um tem em média 10 minutos, totalizando 4 horas de duração. A temporada foi assistida uma vez tendo por foco a identificação das questões da sexualidade e posteriormente comprendidas a partir da teoria freudiana.

Resultados: Os principais resultados obtidos na pesquisa foram que em determinados personagens apresentam um olhar sobre a sexualidade como o proposto por Freud, ou seja, todos nascemes bissexuais e durante o desenvolvimento físico/emocional, reprimimos o desejo pelo mesmo sexo ou o desejo pelo sexo oposto ao seu. O desenho discute uma sexualdade tal como convive-se no dia de hoje, novas formas de relação que precisam ser trabalhadas junto aos jovens.

Conclusões: Acredita-se que o desenho Steven Universo possa ser aprofundado para ser trabalhado junto as crianças e jovens como uma atividade de apoio para a reflexão da sexualidade.

Palavras chave: Steven Universe. Psicanálise. Sexualidade. Desenho Animado. 